support them, either from the Local Government medical officer or a competent and qualified veterinary surgeon.

It seems that much opposition to the Act was displayed at its initiation by various persons connected with the breeding and sale of stock, and it was found necessary, in addition to the seizure and destruction of diseased animals, to institute proceedings for the recovery of penalties, in order that their responsibility in this matter might be brought home to graziers. As the provisions of the Act became better known it was realised that the trade generally would benefit by its strict enforcement, and that ultimately the flocks and herds of the colony would be considerably improved. In no case had the Board instituted any prosecution, except in cases in which the disease was external and clearly observable by any person possessing an ordinary knowledge of stock.

The administration of the Act has raised many points of scientific interest and practical importance, to elucidate which it was necessary to undertake microscopical and experimental investigations, chiefly in the Board's laboratories. The diseases so investigated were tubercle, actinomycosis, abscesses, cancers, dermoid affections, and contagious pneumoniz. The colony must derive great benefit from the operation of this Act, not only in protecting the public health, but also in limiting the prevalence of disease among the domestic animals and their products.

\section{PATHOLOGICAL AND CONGENITAL ANOMALIES IN BRAINS OF CRIMINAL WOMEN.}

By Signor Willitam Ferrero, MILAN.

IT is a fundamental law of the Italian school of criminology that the moral derangement of the criminal is closely connected with physical abnormalities, among which those of the brain, as the organ of the mind, are no doubt the most important, and consequently Professor Lombroso and myself, who are engaged in studying criminal women, have not failed to devote particular attention to the subject. The facts ascertained so far have certainly not been sufficient to enable us to draw any decisive inference on the point, but it will not be uninteresting to know what we as well as other scientific men have found in such researches in the pathology of the brains of criminal women, and the more so as those facts might at least form the point of departure for further researches. The anomalies that have been met with in the brains of criminal women are of two kinds-viz., ( $\alpha$ ) pathological, produced by a disease contracted individually ; and $(\beta)$ congenital, a consequence of imperfect development, generally resulting from hereditary causes. Pathological anomalies were found by us in ten among thirty-eight criminal women's brains examined, and among all the anomalies encountered the following were the most noticeable: (1) dilatation of the lateral ventricles; (2) hæmorrhages in the frontal part of the hemispheres; (3) thickening of the cranial and spinal dura mater ; (4) meningo.encephalitis ; (5) apoplexy of the brain from hæmorrhage into the lateral ventricles; (6) syphilitic gummata in the form of two small oval masses adhering to the peduncle of the cerebrum and to the inner surface of the optic chiasm; (7) abscess in the brain, which had produced in the last months of life paralysis of the extremities; (8) cerebro-spinal meningitis, with the lateral ventricles containing an excess of turbid Auid and lymph; (9) tumour of soft consistence between the origins of the third and fourth pair of cranial nerves; and (10) abscess in the cerebellum. More than those thirty-eight brains hare not been examined, the women that die in prison being few. It is impossible, of course, to make any safe deductions from so slight a number of observations, but we can hardly be said to overstep the limits of cautious reserve with which an investigator has to proceed in stating that a proportion of ten cerebral diseases ending almost always in death out of thirty eight brains examined is a large and remarkable one. If future researches confirm the hypothesis that the probability of criminal women being affected by some cerebral disease is very great, a most important fact, as regards both pathology and criminology, will have been established.

With respect to congenital anomalies, the discoveries of Min-

gazzini, who carefully examined seventeen brains of crimina women, are very useful. In one of those brains (that of a "submicrocephalic " murderer) the vertical and anterior branch of the fissure of Sylvius was absent; in another the gyrus canei was very superficially placed; in a third brain the middle frontal convolution joined almost at its beginning the superior, from the external and deep side of which a furrow ran transversely to the anterior part of the inferior frontal convolution. The brain of a matricide showed a prolongation of the inter-parietal sulcus crossing transversely the occipital lobe and a corresponding prolongation of the calloso-marginal sulcus. In the right hemisphere of another criminal woman's brain the inter-parietal sulcus appeared as a furrow in the shape of a cross, which divided the superior and inferior parietal lobules; the parietal convolution was at the left divided transversely into two secondary gyri by a sulcus bifurcated in its upper part and running parallel with the fissure of Rolando. In two cases the parallel fissure was connected with the parietooccipital fissure; and in another the parallel fissure, after having thrown off a descending branch, crossed the hemisphere right through and reached its free margin. In one case the sulcus extremus was absent ; in two other cases the calcarine fissure and the collateral fissure ran into each other; and, lastly, in one brain the sulcus extremus and an inferior branch of the bifurcated calcarine fissure were in connexion.

As Mingazzini examined also thirteen brains of male criminals it may be interesting to draw a parallel between these and the seventeen female cases just instanced by means of the following table :-

Parts of brain.

The rertical and anterior branch of the

fissure of Sylrius absent

Gyrus cunei superficially placed

Anomalies of the frontal lobes

The parietal asesnding convolution

divided in two secondary gyri

The parallel fissure in connexion with the parieto-occipital fissure The parallel fissure reaching the free margin of the lobe

The sulcus extremus absent.

The calcarine fissure and the collaterai fissure in connexion.

The sulcus extremus and an "̈inferior

branch of the bifurcated calcarine

Besides these data there are a number of isolated cases of observations on brains of criminal women, which showed an accumulation of anomalies, both pathological and congenital, and struck very forcibly the investigators who studied them. Ferrier described, as follows, the brain of a criminal who used to practise tribadism: the right hemisphere was by forty grains lighter than the left; the fissure of Rolando was cut through by a deep furrow which sprang from the ascending frontal convolution, the latter being in a state of atrophy ; and in the third convolution be found a depression with several gyri smaller and of firmer consistence than the usual structure of the convolution. Ferrier explains the latter anomaly as resulting from inflammation, but observes that the former irregularity at the fissure of Rolando seemed to him to be very remarkable and rare, as be encountered it but in one case out of 800 brains of normal men. Flesh found in the brain of a female thief, besides pachymeningitis, the ascending frontal convolution interrupted at the left, a central lobe of the cerebellum shaped like those of some species of mammifers, and two furrows which shooting out forwards crossed the horizontal convolutions right through the whole length of the hemispheres. Hotzen published in his "Psychiatric Archives" a number of interesting observations on the brain of Mary Köster, who, at the age of eighteen years, killed her mother in order to rob her of a small sum of money. Besides some traces of pachymeningitis, her brain showed a most curious atrophy of the cerebral cortex; the anterior central convolution was crossed by many small furrows, and the posterior was broken through by one groove by means of which the fissure of Rolando and the inter-parietal fissure became connected. The fissure of Rolando did not reach down to the fissure of Sylvius; both central convolutions, the anterior and posterior, were crossed by a deep broad gap, which united the inter-parietal fissure and the first frontal sulcus. This was undoubtedly a case of atrophy, resulting from congenital (and hereditary) degeneration of the brain; the numerous irregular farrows, indeed, do not indicate a superior degree of evolution, as do the convolutions, because they do not increase the cerebral substance, but very considerably lessen it. Congenital (and hereditary) degeneration was in this case also proved by some other 
characteristics of the brain, of which the following two merit particular mention---viz., that all the convolutions were small, and more especially the frontal, which were evidently very little developed; and that the cerebellum was incompletely covered by the two hemispheres.

The cases referred to are undoubtedly exceptional and might be considered as monstrosities, but they warrant the inference that the anomalies, which have here come under such striking notice, may exist in the brains of all criminals, although in a smaller degree and less marked, and that further and keener researches may bring them to light. Medical men attached to prisons could better than any others supply very valuable information in connexion with their necropsies, and it would be a boon indeed if these few lines contributed to induce some of them to do so.

THE FELLOWS AND MEMBERS OF THE ROYAL COLLEGE OF SURGEONS AND THE REPORT OF THE ROYAL COMMISSION ON THE PROPOSED GRESHAM UNIVERSITY IN LONDON.

THE Council of the Royal College of Surgeons of England decided at its meeting on the 8th inst. to summon separate meetings of Fellows and Members of the College for Monday and Tuesday, the 19th and 20th inst., to consider the recently issued report of the Commissioners appointed to consider the Draft Charter for the proposed Gresham University in London. The meetings are summoned in pursuance of the following resolution adopted by the Council on Jan. 12th, 1893- viz. :

"That, in order to ascertain the views of the Fellows and Members of the College on the position which in their opinion this College should hold in the proposed Teaching University for London, separate meetings of Fellows and Members be convened at an early date after the report of the Gresham Royal Commission has been made public." The business of the meeting will be confined to:

1. The consideration of the following resolution adopted by the delegates of the Royal College of Physicians and this College, and referred to the meeting by the Council-viz.: "That the delegates of the two Royal Colleges do cordially approve of the general provisions in the Report of the Gresham University Commission, particularly in so far as they relate to the said Colleges, regarding them as being in accordance with the principles which the Colleges have hitherto affirmed and accepted, and as constituting the most comprehensive and academic scheme hitherto proposed."

2. "The consideration of any motions relating to the position of the College in the proposed University which may be introduced to the meeting by Fellows of the College." It is added in the circular issued to the Fellows: "It has appeared to the Council desirable that the Fellows should be conferred with on this question at as early a date as possible, and that the Regulation of the Council relating to meetings of Fellows, limiting the time within which motions to be introduced by Fellows must be sent in to twenty-one days before the meeting, should be suspended. Motions, therefore, which must be signed by the mover, or the mover and other Fellows, will be entered on the agenda of the meeting if received by the Secretary before 1o'clock P. M. on Saturday, the 17th, and if declared by the President to be in order."

Whilst according to the Council of the College its due share of credit for abstaining from expressing an approval of the report of the Royal Commission before submitting it to the Fellows and Members of the College, we cannot but observe that in the present instance the Council has erred as much on the side of undue haste as it has hitherto been in the habit of erring upon the side of undue delay in consulting the Fellows and Members. The report of the Royal Commission is very long and complicated, and the interval between the announce ment of the meetings and the dates fixed for the meetings is far too short to allow the Fellows and Members to "read, mark, learn, and inwardly digest" it, and formulate resolutions for discussion at the meetings. Hastiness of this kind tends to defeat the objects for which the meetings are ostensibly called, and must render any approval or disapproval of the report expressed at the meetings comparatively valueless. Moreover, it would have been advisable for the Council to have issued to the Fellows and Members some explanatory statement both defining the position which the College has hitherto taken up in reference to facilitating the acquisition by London medical students of University degrees, and to the effect which the scheme adrocated in the report will have in advancing this end. The choice of such early dates as the 19th and 20th inst. for the meetings of Fellows and Members quite precluded the Council from appointing a committee to draw up a statement of the kind indicated, and we fear that the result of the meetings will prove the truth of the old adage "the more haste the less speed." What was the recessity for this haste is not at all apparent. Undoubtedly if the Fellows and Members of the College feel on the 19th and 20th inst. that sufficient time has not been given to them to master the report of the Commission and to arrive at a mature judgment on the intricate points involved in it they will do well to express this opinion and to ask the Council to adjourn the meetings for a few weeks in order to afford time for adequate delibera. tion. It is placing the Fellows and Members of the College in an entirely false position to ask them to deliver an opinion upon the merits of a complicated scheme after so short a notice.

\section{THE INTERNATIONAL SANITARY CONFERENCE. \\ (From our Spectal Correspondinte)}

A GREAT deal has been said concerning the attitude of the United States delegates. From the fact that the American Government has not yet abandoned the principle of quarantine, it has been concluded that the American delegates at the Conference have upheld old-fashioned ideas and advocated a reactionary policy in respect to sanitation. This led me to make inquiries, and the following is the substance of the answer I have received from Dr. Edward O. Shakespeare, one of the delegates of the United States Government to the Paris Sanitary Conference:--

In response to your note of the 2 nd inst., enclosing an extract from the Daily Nens, London, I can only say that the seal of secrecy placed upon the proceedings of the International Sanitary Conference of Paris for this time prevents me from doing more at present than making a general and specific denial of the statement referred to. When the seal of secrecy shall have been removed from the proceedings of the Conference the procès verbal will, I think, convince any unbiased mind that the representatives of the United States have worked earnestly and loyally to forward the programme suggested by the Government of France for the consideration of the Conference. I am gratified to learn that the Editors of THE LANCET were inclined to doubt the trath of the statement referred to. The Editors of THE LANCET and other medical newspapers, I bave reason to know, as a rule, evince far greater knowledge of the sentiments and work of American physicians and sanitarians, and a far greater feeling of fair dealing in judging of the acts of Americans in general, than is usually evinced by the British secular press.

From other sources I hear that the American delegates at the Conference merely made a statement. What America desires or intends to do with regard to emigration cannot be discussed by the present Conference. The delegates of the various Powers have no instructions on the subject. It may also be asked, Why should America ask Europe to protect her from cholera? England, France, and other countries did not ask Hamburg to protect them from this disease. There is a feeling that America is big enough to take care of 